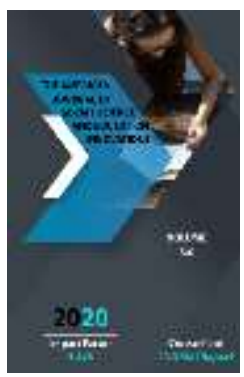

\title{
Abstraction And Language Model
}

\author{
Bazarov Oybek Odilovich \\ Candidate Of Philological Sciences, Kokand State Pedagogical Institute, Uzbekistan
}

Journal Website:

http://usajournalshub.c

om/index,php/tajssei

Copyright: Original content from this work may be used under the terms of the creative commons attributes 4.0 licence.

\section{ABSTRACT}

This article discusses abstraction, its essence, methods of abstraction and the role of abstraction in the formation of language models.

\section{KEYWORDS}

Abstraction, Essence, Logical cognition, phoneme, lexeme, morpheme.

\section{INTRODUCTION}

It is known that in human activity, cognition is manifested in two types, namely, vital and scientific cognitive status. Cognition of life is primary, in which man seeks to satisfy his needs for survival and protection. The thing about this relationship is that information is formed about the beneficial and harmful properties of events to people. Scientific or theoretical knowledge is a high-level activity of thinking in which a person tries to know the essence of things, regardless of whether they are useful or harmful. The essence is the phenomenon that manifests in any situation the certain quality, the identity of what makes the thing, that is, the necessary connections inherent in its internal structure, the integrity of the 
relationship. The basis of scientific knowledge is practice, the essence, man's active relationship with the world around him, his influence on it, his attempt to change things and events in the way of his own interests. This process serves as a basis for the gradual development of cognition from the emotional stage to logical cognition, the transformation of vital cognition into scientific (theoretical, scientific) study.

\section{THE MAIN FINDINGS AND RESULTS}

Logical knowledge is the knowledge of the universe through high generalizations, abstractions. It involves logical units such as concepts, judgments, and conclusions, in which words, sentences, and complex syntactic units, which are units of language and speech, are directly involved. Language (word, sentence) and logic (concept, decision) are mutually conditioned, inextricably linked phenomena that do not occur without each other. Without taking into account the dialectical relationship between logic and language, it is impossible to ensure the effectiveness of research in the areas of logic and language.

The need to preserve or memorize the concepts that are increasing in the mind in the course of human development has led to the need to further narrow, shorten, abstract these concepts. This was achieved by dropping secondary, insignificant characters in the scope of the primary (primitive) concepts and naming them concepts. On this basis, the concept began to be transformed into meaning, which was its abstract stage. For example, in the phrase, "This tree grows well," the word "tree" is rich in meaning, that is, a plant species that reflects certain characteristics at a particular time. If we take the lexeme of the word "tree," which is taken out of a sentence or sentence and is in an ideal position in the vocabulary of our memory, we realize that its meaning consists mainly of general, abstract symbols such as "perennial, hard-bodied, branched, plant." The same series of abstract symbols representing the skeleton of millions of "tree" concepts forms the meaning of a word (lexeme) that is a unit of language. The convenience of this abstract meaning for reporting is that the speaker can apply this concise basic meaning to any type of "tree" concept, enrich it as much as he wants (according to the characteristics of a particular objective tree) with secondary characters, and achieve the truth of the message about a particular tree.

It is natural that the process of cognition goes from simple to complex, from concrete to abstract. We can see this clearly in the interaction of concepts and the meanings formed on the basis of them. It is self-evident that man, first of all, has created knowledge about events, something that directly affects his five senses, and has created meanings from these, that is, concrete types of concepts. Usually, meanings derived from concepts such as "pear", "bread", and "machine" are primary to meanings derived from abstract concepts such as "will", "love", and "honesty". We can also see different levels of concreteness and abstraction in them if we pay attention to the content of concrete concepts and meanings as well as abstract concepts and meanings. In particular, while the meanings of noun phrases are more specific than adjectives, the meanings of verbs are more precise than forms. While abstract concepts and meanings relate to a particular part of a noun phrase, numbers and rhymes represent absolute abstract meanings as linguistic units, and so on. Abstraction has reached its peak in concepts 
and meanings such as "matter", "essence", "law", which represent categories.

Abstraction has arisen as a result of the continuous development of perception from intuition to perception, from perception to imagination, from imagination to understanding, in turn, the concepts individually, separately and more generally and most generally. The highest forms of abstraction are categories and laws. Because they reflect the most general, important aspects of the system and structure of the universe (thing, event, relationship). Therefore, since the dialectic of the stages of specificity $\rightarrow$ individuality $\rightarrow$ commonality is true, we can carry out the process of cognition in the direction of commonality $\rightarrow$ individuality $\rightarrow$ specificity with the help of thinking. In turn, the unity and struggle of contradictions, which reflect high abstractions, generalizations, the transition of quantitative changes to qualitative changes, and the laws of negation and the categories that serve them serve as a methodology (general guide) for scientific knowledge. Language models and linguistic modeling, which are one of the most pressing problems of modern linguistics, can be successfully solved only through theoretical interpretations with the help of methods (analysis, synthesis, induction, deduction, analogy), dialectical law and categories.

As a result of the distinction between language and speech in linguistics, the doctrine emerged that language consists of a system of invariant units, i.e. models. In this regard, language units, levels, and integrity began to be thought of as models. So, since every phoneme, lexeme, morpheme, phrase, and sentence exists in the form of patterns in our memory, the construction of these patterns, without knowing in detail the possibilities of their components, is not only the language but also the variants that form that is, it is difficult to comprehensively understand the characteristics of speech units either. So, the left-hand sides of equations such as lip / lip + explosive + soundless $=p$, determiner + definite $=$ phrase, possessive + cut $=$ sentence, paragraph + paragraph = text, man + weapon = warrior are language models.

In linguistics, the problem of modeling and modeling has received serious attention since the 1960s. But a successful interpretation of the model problem is inextricably linked to two factors. The first is the relative completeness of linguistics in the more complete qualitative and quantitative study of its object (language), and the second is the ability of linguists to use mathematical and logical concepts at a high level. Important features of language levels and units have now been studied in detail. Hence, the theoretical foundations for language modeling are sufficient. But it cannot be said that linguists have mastered the philosophical, logical, mathematical knowledge necessary for modeling. Thus, the current urgent task is to form a philosophical, mathematical linguistics and to raise linguistics to the highest level on the basis of model teaching.

Models, which are in fact an abstract unit, are formed by comparing speech variants, imagining various insignificant, additional phenomena, identifying recurring, important, invariable aspects of colorful speech variants and combining them into an internal whole, in which the leadership of the deduction method is of great importance. 


\section{CONCLUSION}

In summary, we can say that as long as each linguistic unit exists in our memory in the form of a model, it means that language consists of a system of hierarchical patterns formed on the basis of part-whole, species-gender relations. Therefore, the main purpose of linguistics is to study language patterns, which are units of system-structural construction of language. The doctrine of the model itself reflects the relative outcome of empirical and theoretical linguistic research. So far, linguistics has mainly noted the important and insignificant features and relations of language and speech units, dividing them into categorical and noncategorical status, the task now is to delve deeper, through models, into the essence of each linguistic unit, level, and whole language mechanism on the basis of these linguistic units, signs, and relations.

\section{REFERENCES}

1. Korshunov A.M. Reflection theory and modern science, Moscow: 1963-- pp. 55-60.

2. Ismailov B. Language and knowledge of the world, Tashkent: 1969. - pp. 93-100.

3. Revzin I.I. Language models, Moscow: 1962.

4. Piotrovski R.G. Modeling phonological systems and methods for their comparison, Moscow: 1966.

5. Nematov H; Sayfullaeva R; Qurbonova M. Fundamentals of structural syntax of Uzbek language. Part 1. Linguistic patterns and valence. Tashkent; 1999 and others. 